\title{
Private telehealth foray into public system
}

$\mathrm{T}$ he launch of an app offering Ontario patients access to family doctors via telephone, text messaging and videolink for $\$ 10$ a month is fuelling debate over the place of privately delivered virtual health care.

The Akira app allows Ontario patients to consult with physicians and grant permission to access app-generated health records, including clinical notes, prescriptions and test results, said Dr. Taha Bandukwala, Akira's chief medical officer. Users can begin a text conversation with a doctor, and doctors can launch a video chat, during office hours six days a week.

During a test this spring, more than 2000 people signed up for Akira and had over 750 doctor consultations, Bandukwala said. "Patients love this. We feel that this will in future be the first touchpoint for primary health care delivery."

Bandukwala cautions that Akira is not intended for medical emergencies or to replace ongoing care by physicians for chronic disease, cancer or other complex care conditions. But it gives patients access to doctors to diagnose and treat many common health problems, such as anxiety or depression, urinary tract infections, rashes and flu.

Physicians are employed by Akira on contract. Patients must be Canadian residents and provide government identification. Patient identity must be confirmed via video link when physicians write prescriptions. An Ontario Health Insurance Plan number is required if the patient is referred for publicly insured specialist care.

Akira's novelty should not be overstated, notes Dr. Karim Keshavjee, CEO of Infoclin, a Toronto-based e-health consultancy. "Lots of people have tried this in Ontario in the past. None of them have found enough traction to become a going concern. Doctors don't have [automatic] access to the patient's medical record, which limits what they can do and say. Other

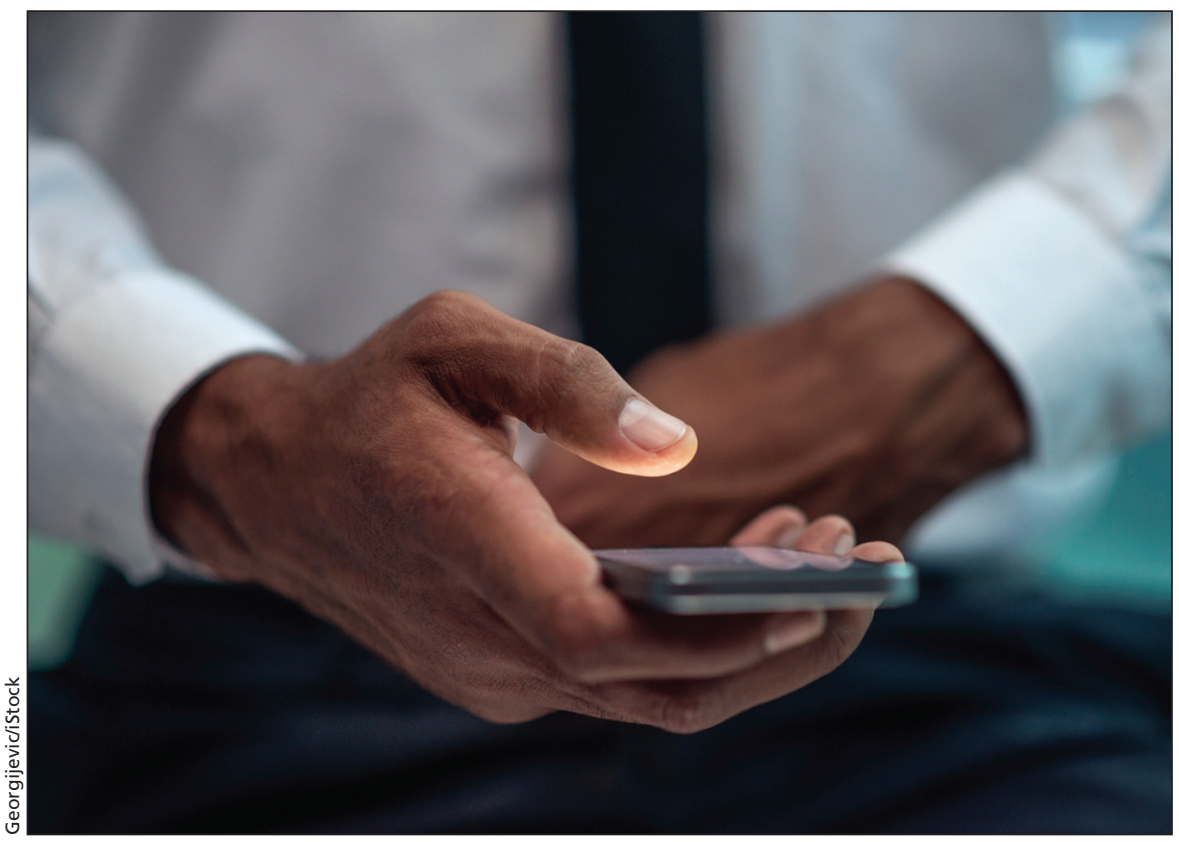

Commercial virtual health care is another attempt to privatize health care, says an expert.

than the prescription part, this is basically like the 1-800 telehealth line."

Dr. David Chan, professor and director of information technology in the Department of Family Medicine at McMaster University, is also skeptical. "This is another attempt to introduce privatization of health care," he said. "This business venture will go away as the majority of citizens in Canada will refuse to pay. [The] public health [system] is not interested because this is new programming and where does the new money come from?"

A variation on virtual health for rural and northern residents is already available: Ontario Telehealth Network (OTN) provided physician access via telephone and videolink in 390000 health care consultations during 2014, avoiding 260 million kilometres of travel for patients. OTN requires that patients visit health care facilities to access telemedicine technologies and medical services; Akira does not.

CEO Ed Brown describes Akira's arrival as a sign that "patients increasingly want care to be delivered on their own terms." He anticipates that in the future half of all health care consultations will be delivered via virtual technologies. "The challenge is to figure out how to deliver it in way that sustains the public health system."

Whether commercial services such as Akira will ever be covered by public health insurance plans is uncertain, said Brown, who notes that British Columbia's experience has been problematic.

In the hope of expanding physician access for underserved communities, the $\mathrm{BC}$ government implemented physician fee-for-service billing codes. Several companies began offering technology platforms to physicians, which resulted in an eightfold increase in physician billing for telemedicine.

When family physicians complained that telemedicine doctors were running "virtual walk-in clinics, rather than providing more desirable holistic primary care," said Brown, the BC Ministry of Health suspended the program in 2014 and launched a review, which has yet to conclude. - Paul Webster, Toronto, Ont.

CMAJ 2016. DOI:10.1503/cmaj.109-5285 